\section{A fractured duodenal self-expanding metal stent in a patient with pancreatic cancer}
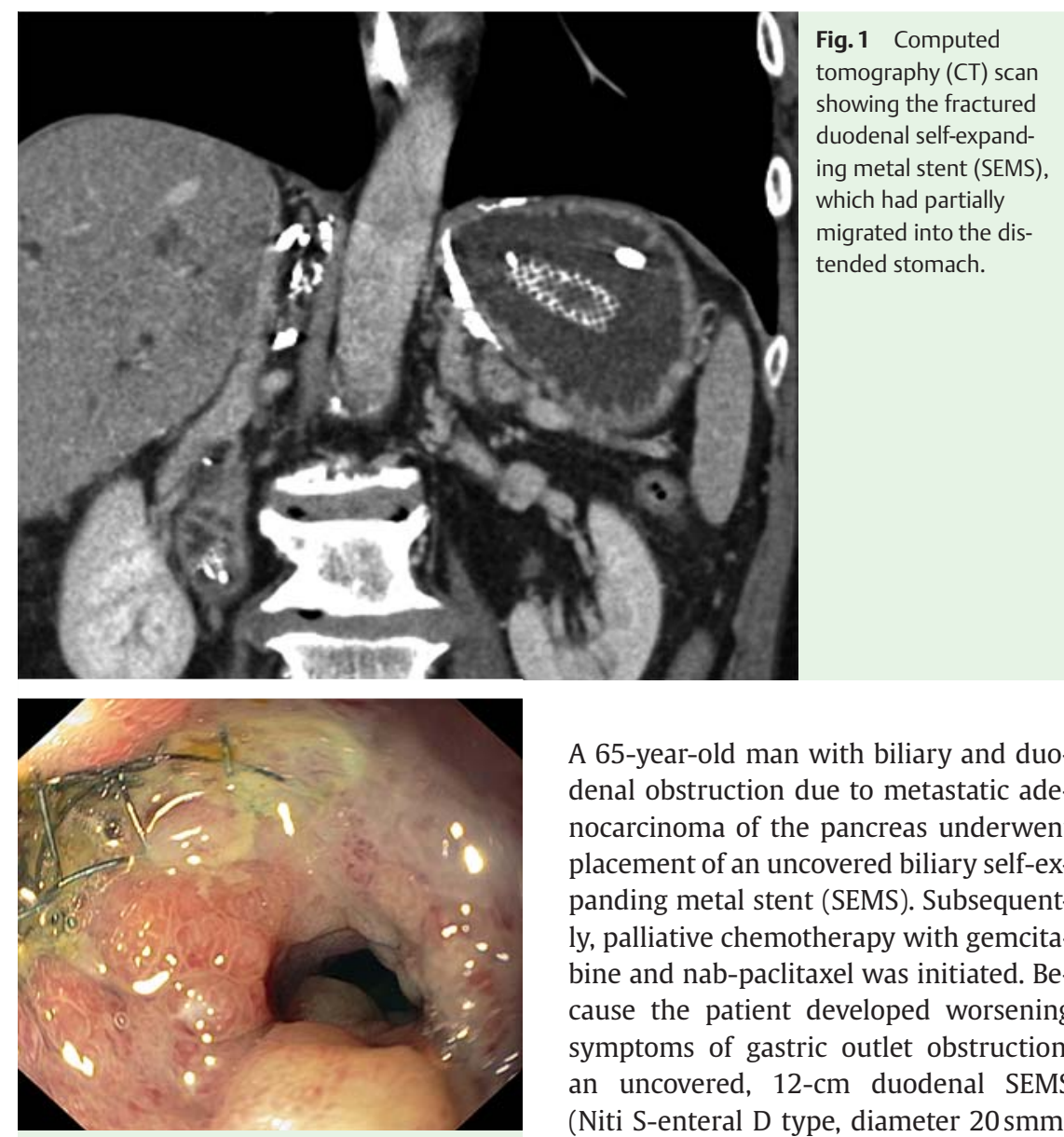

Fig. 2 Endoscopic view of the remnant part of the duodenal self-expanding metal stent (SEMS), which was no longer patent.

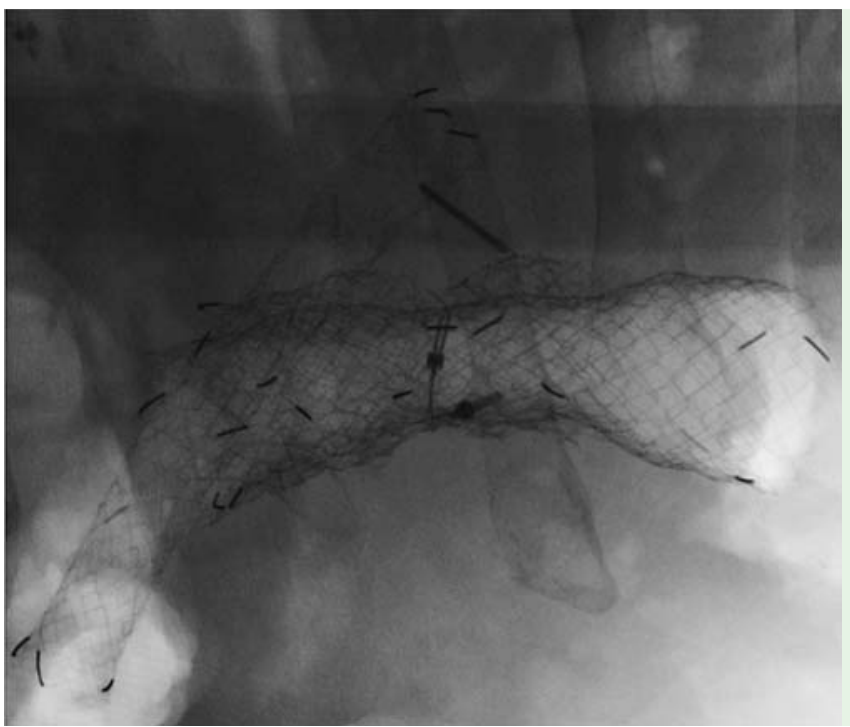

After 2 months a partial tumor response was documented; however, 6 weeks later he presented again with recurrent symptoms of gastric outlet obstruction. Computed tomography (CT) demonstrated fracture of the duodenal SEMS, which had partially migrated into the distended stomach ( Fig. 1). A remnant of the SEMS was still in place but was not patent ( $\bullet$ Fig.2). After the migrated piece of the SEMS had been removed with a snare, an additional uncovered 8-cm SEMS (same type, diameter $22 \mathrm{~mm}$ ) was placed in the remnant duodenal SEMS ( $\bullet$ Fig. 3). Examination of the removed piece of SEMS showed that the wire mesh was broken ( $\bullet$ Fig.4). The biliary stent remained patent. After this procedure, the patient was able to eat soft food again.

Placement of a duodenal SEMS is the standard palliative treatment for malignant gastric outlet obstruction and results in prompt relief of symptoms. Distal stent migration can occur in up to $56 \%$ of patients who have covered SEMSs placed $[1,2]$. In contrast, stent migration is rare in patients who have had uncovered duodenal SEMSs placed, being reported in less than $2 \%$ of patients in a recently published prospective multicenter study [3]. An extremely rare adverse event of such SEMSs is complete stent fracture and subsequent migration of the broken part. To date, 12 cases of complete fracture of a SEMS, mostly esophageal SEMSs, have been reported [4].

In cases where symptoms of gastric outlet obstruction recur after initially successful placement of a duodenal SEMS, tumor ingrowth, stent migration, and stent fracture, as reported in the present case, should all be considered.

Fig. 3 Radiographic images following the extraction of the migrated part of the self-expanding metal stent (SEMS) showing a second duodenal SEMS positioned in the remnant of the original SEMS. The patent biliary SEMS, which remains in place, is also shown.
Endoscopy_UCTN_Code_CPL_1AH_2AD

Competing interests: None Jörg Trojan ${ }^{1}$, Thomas J. Vogl'
Stefan Zeuzem ${ }^{1}$, Jörg G. Albert ${ }^{1}$

${ }^{1}$ Department of Gastroenterology, Goethe University Medical Center, Frankfurt/Main, Germany

2 Department of Diagnostic and Interventional Radiology, Goethe University Medical Center, Frankfurt/Main, Germany 


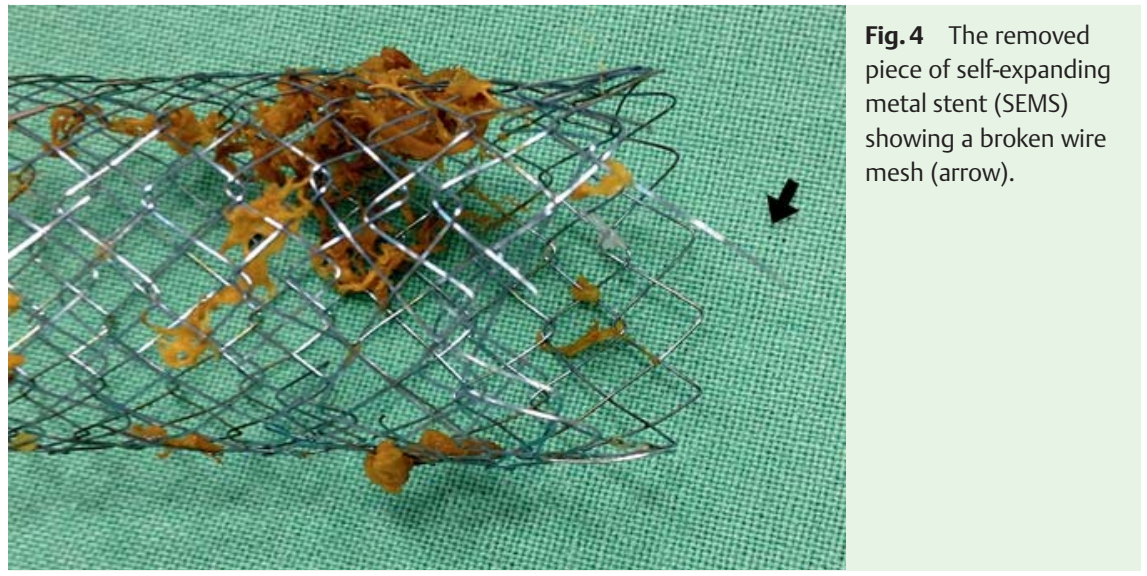

\section{References}

1 Woo SM, Kim DH, Lee WJ et al. Comparison of uncovered and covered stents for the treatment of malignant duodenal obstruction caused by pancreaticobiliary cancer. Surg Endosc 2013; 27: 2031 - 2039

2 Waidmann O, Trojan J, Friedrich-Rust M et al. SEMS vs cSEMS in duodenal and small bowel obstruction: high risk of migration in the
4 Khara HS, Diehl DL, Gross SA. Esophageal stent fracture: case report and review of the literature. World J Gastroenterol 2014; 20: $2715-2720$

\section{Bibliography}

Dol http://dx.doi.org/

10.1055/s-0034-1377364

Endoscopy 2014; 46: E386-E387

(c) Georg Thieme Verlag KG

Stuttgart · New York

ISSN 0013-726X

\section{Corresponding author \\ Jörg Trojan, MD}

Department of Gastroenterology Goethe University Medical Center Theodor-Stern-Kai 7

D-60590 Frankfurt

Main

Germany

Fax: +49-69-63016448

trojan@em.uni-frankfurt.de 